\title{
Rediscovery of Cenopalpus lineola (Canestrini and Fanzago, 1876) in Hungary (Acari Tenuipalpidae)
}

\author{
J. KONTSCHÁN ${ }^{1 *}$, E. KISS ${ }^{2}$ and G. RIPKA ${ }^{3}$ \\ ${ }^{1}$ Plant Protection Institute, Centre for Agricultural Research, Hungarian Academy of Sciences, \\ H-1525 Budapest, P.O. Box 102, Hungary \\ ${ }^{2}$ Plant Protection Institute, Szent István University, H-2100 Gödöllő, Páter Károly str. 1, Hungary \\ ${ }^{3}$ National Food Chain Safety Office, Directorate of Plant Protection, Soil Conservation and Agri-environment, \\ H-1118 Budapest, Budaörsi út 141-145, Hungary
}

(Received: 22 January 2020; accepted: 18 February 2020)

\begin{abstract}
The pine pest, Cenopalpus lineola (Canestrini and Fanzago, 1876) was discovered after 45 years again in Hungary. Proto-, deutonymphs, male and female specimens were collected, therefore a new and detailed re-description are presented with description of the leg chaetotaxy of the immature stages.
\end{abstract}

Keywords: Flat mite, occurrence, morphology, Hungary.

The flat mites or tenuipalpids are a very diverse group of plant-feeding mites occurring in most regions of the Earth. Numerous species are known as pests, especially from the genera Brevipalpus, Cenopalpus, Dolichotetranychus, Raoiella and Tenuipalpus. Contrary with the large economic impact, the majority of the Central European countries are poorly known from flat mite point of view. Hungary is no exception, only twenty species are recorded (Kontschán and Ripka, 2017, 2018). Majority of these 20 species are presented more than 40 years ago, so their current occurrences are very questionable.

One of these questionable species is the pine pest, Cenopalpus lineola (Canestrini and Fanzago, 1876) which was reported by Bozai (1974) from two different localities of Hungary, and later has never been found again.

Cenopalpus lineola was described by Canestrini and Fanzago (1876) in Italy, but later, several times was re-described (see Mesa et al., 2009). These re-descriptions were incomplete because the description of the leg chaetotaxy was omitted, therefore our aim is to give a new description and a note to the ontogeny of leg chaetotaxy following Seeman and Beard (2011). 


\section{Materials and Methods}

Specimens of Cenopalpus lineola were collected in planted Scots pine tree (Pinus sylvestris L.) close to village Csévharaszt (Pest county) using the beating method. The fallen mites were placed into $75 \%$ ethanol on the site. In laboratory the specimens were placed into lactic acid for a week and then slide-mounted in Hoyer's medium. The specimens are deposited in the Plant Protection Institute, CAR, HAS, Budapest.

All specimens were examined by a Leica 1000 scientific microscope; the illustrations were made with the aid of a drawing tube on this microscope. All measurements and scales are given in micrometers.

\section{Results}

Cenopalpus lineola (Canestrini and Fanzago, 1876)

(Figs 1-8)

Material examined. Three females, one male, one deutonymph and one protonymph. Hungary, Csévharaszt (Central Hungary), from Scots pine trees, 12 July 2018, leg J. Kontschán.

Diagnosis (Based on female). Tarsal claws uncinate. Anterior margin of prodorsal shield with paired projections, prodorsum weakly sculptured, with few irregular lines. Opisthosoma with polygonal reticulation. Propodosomal and opisthosomal setae wide and serrate, except smooth and needle-like setae $d l$ and $e 1$. Length of dorsal setae 6-14.

Description. Female $(n=3)$.

Idiosoma reddish-brown, oval in shape, body measured from $v 2$ to h1 290-300; from tip of rostrum 330-340; width 180-190 near setae sc2; distance between setae sc2 170-175; length of legs I-IV (without coxa), leg I 130-138, leg II 105-109, leg III 98-103, leg IV 90-94.

Dorsum (Fig. 1): Anterior margin of prodorsal shield with paired projections covered by oval pits, depth of notch 14-15. Propodosoma finely lineate. Opisthosoma with polygonal reticulation. Propodosomal and opisthosomal setae serrate, except $d 1$ and $e l$ which short and smooth. Prodorsal setae $v 2$ longer than half distance between their bases. Length of dorsal setae: v2 22-23, scl 16-18, sc2 21-23, cl 15-16, c2 17-19, c3 18-19, dl 8-9, d3 17-19, el 8-9, e3 17-19, f2 17-18, f3 16-18, hl 14-15, h2 17-18.

Venter (Fig. 2a): Surface of ventral idiosoma with longitudinal and transversal striations. Genital and anal plates smoothly reticulated. Length of ventral setae, $1 a$ 29-32, $3 a$ 11-12, 4a 35-39, $1 b$ 12-14, 2 b 10-11, 3b 6-9, 4b 7-9, 1c 11-12, 2c 25-28, ag 7-9, g1 7-8, g2 7-8. All ventral setae simple and smooth. Pseudanal setae serrate and 6-8 long.

Gnathosoma (Fig. 2b): Setae $m$ on subcapitulum 3-4 long. Palp setal counts: tarsus with one solenidion, two eupathidia and a seta, tibia and genu with one-one dorsal setae. All setae smooth.

Legs (Fig. 2c-f): Setal formula for leg I-IV (coxae to tarsi): 3-1-4-3-5-9, 2-1$3-2-4-9,2-2-2-1-3-5,2-0-1-0-3-5$. A part of setae serrate. Solenidia on tarsi I and II 15-20 long, finger-like. Tarsal claws uncinate and empodium pad-like. 


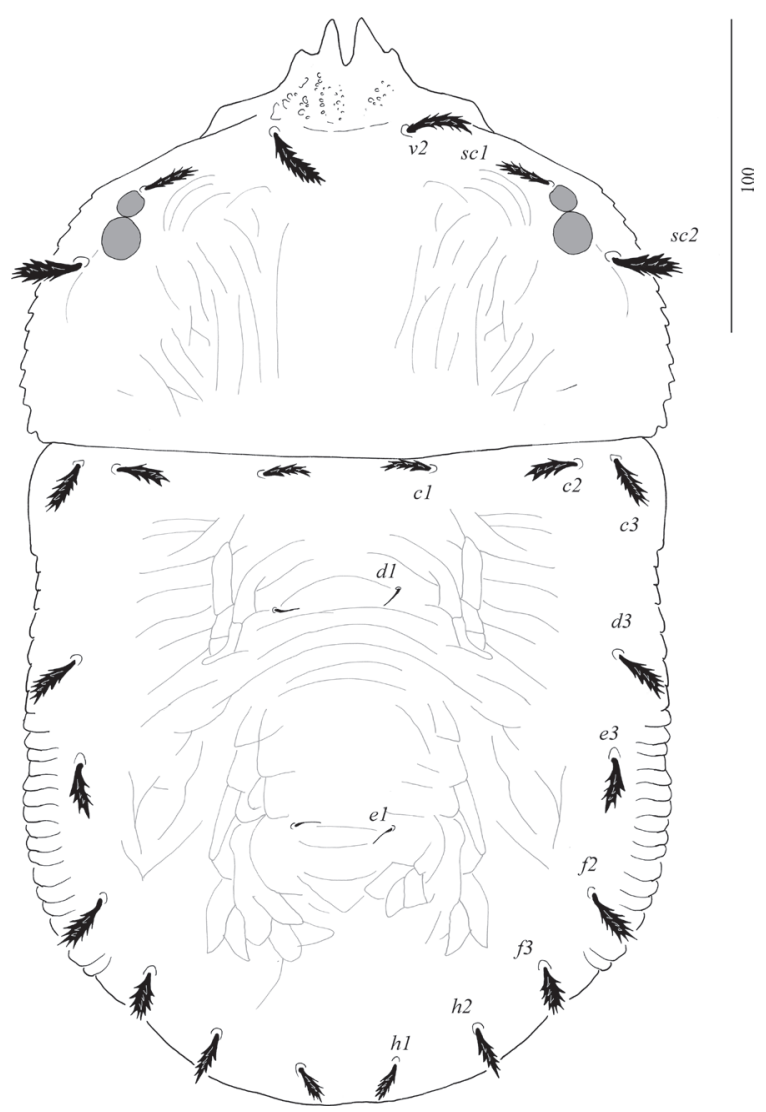

Fig. 1. Dorsal view of Cenopalpus lineola (Canestrini and Fanzago, 1876), from Hungary, female

Male $(\mathrm{n}=1)$

Idiosoma reddish-brown, oval in shape, body measured from $v 2$ to $h 1285-288$; from tip of rostrum 260; width 145 near setae $s c 2$; distance between setae $s c 2120$; length of legs I-IV (without coxa), leg I 108-110, leg II 85-87, leg III 72-75, leg IV 80-83.

Dorsum (Fig. 3): Anterior margin of prodorsal shield with paired projections with two lateral edges, depth of notch 7. Propodosoma smooth. Propodosomal and opisthosomal setae serrate, except $d l$ and $e l$ which short and smooth. Prodorsal setae $v 2$ shorter than half distance between their bases. Length of dorsal setae: v2 22-23, sc1 16-18, sc2 21-23, c1 15-16, c2 17-19, c3 18-19, d1 8-9, d3 17-19, el 8-9, e3 17-19, f2 17-18, f3 16-18, h1 14-15, h2 17-18.

Venter (Fig. 4a): Surface of ventral idiosoma with transversal striations. Genital and anal plates smoothly reticulated. Length of ventral setae, $1 a$ 29-32, 3a 11-12, $4 a$ 38-40, lb 7-8, 2b 8-9, 3b 8-9, 4b 9-10, 1c 11-12, 2c 18-20, ag 25-26, g1 7-8, g2 7-8. All ventral setae simple and smooth. Pseudanal setae serrate, all 6-8. 

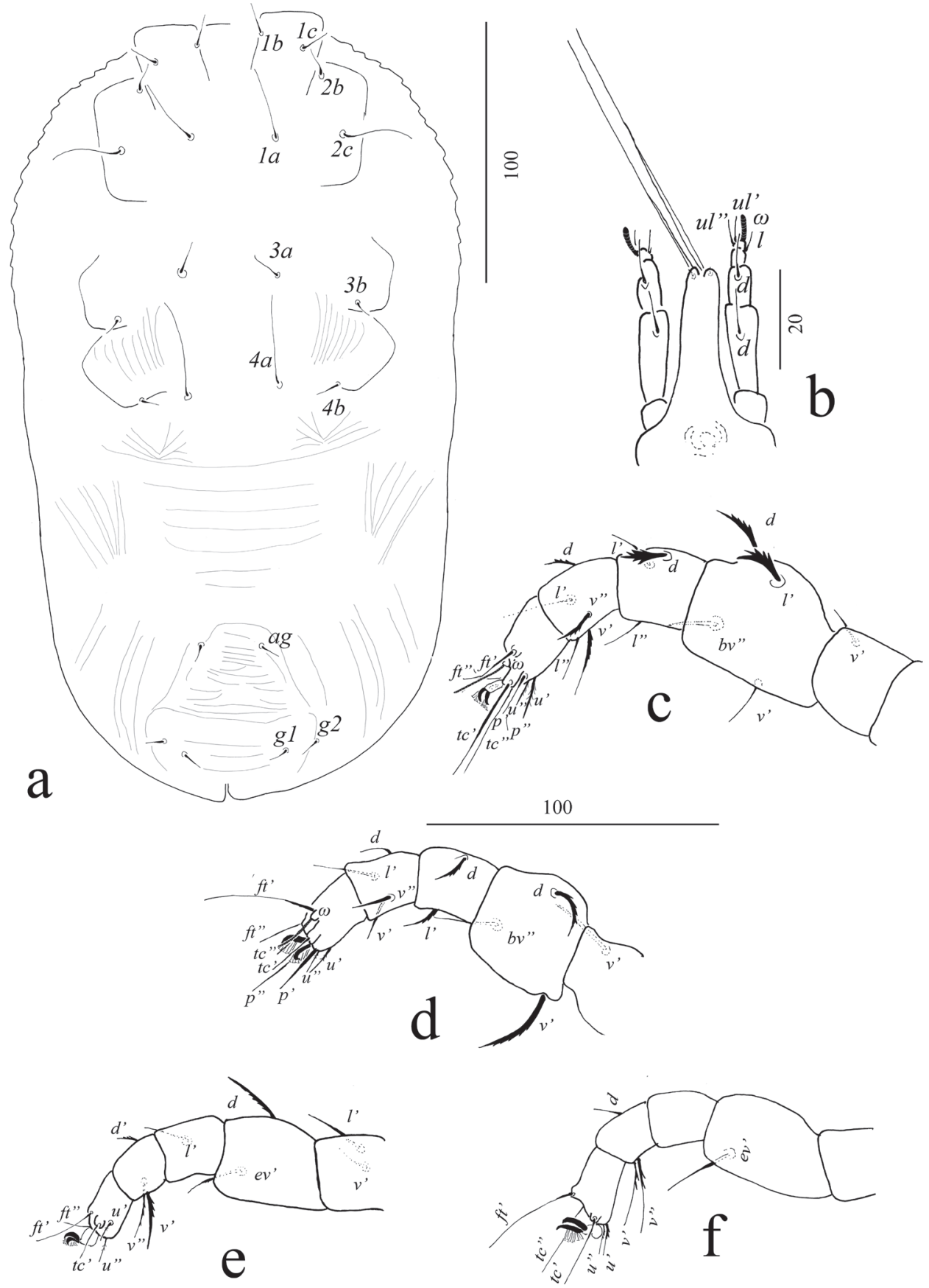

Fig. 2. Cenopalpus lineola (Canestrini and Fanzago, 1876), from Hungary, female: a: ventral view of idiosoma, b: dorsal view of gnathosoma, c: dorsolateral view of leg I, $\mathrm{d}$ : dorsolateral view of leg II, e: dorsolateral view of leg III, f: dorsolateral view of leg IV. 


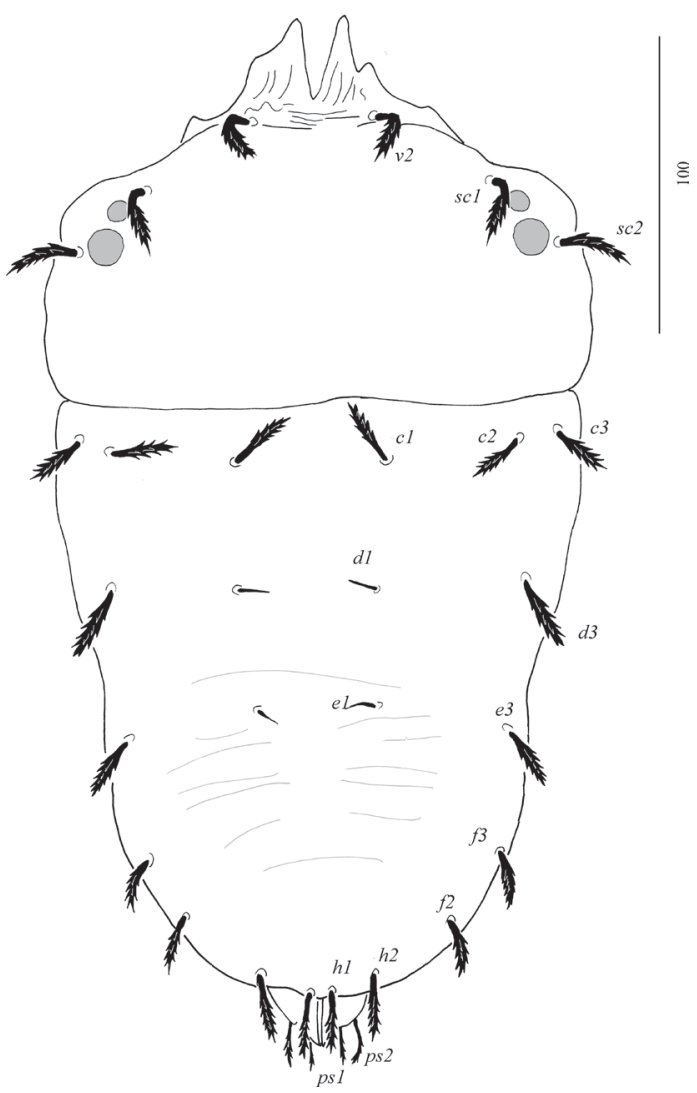

Fig. 3. Dorsal view of Cenopalpus lineola (Canestrini and Fanzago, 1876), from Hungary, male

Gnathosoma (Fig. 4b): Setae $m$ on subcapitulum 3-4 long, palp setal counts: tarsus with one solenidion, two eupathidia and a seta, tibia and genu with one-one dorsal setae. All setae smooth.

Legs (Figs 4c-f): Setal formula for leg I-IV (coxae to tarsi): 3-1-4-3-5-9, 2-1$4-3-5-9,2-2-2-1-3-5,2-1-1-0-3-5$. A part of setae serrate. Solenidia on tarsi I and II 16-22 long, finger-like. Tarsal claws uncinate and empodium pad-like.

Deutonymph $(\mathrm{n}=1)$

Idiosoma reddish-brown, oval in shape, body measured from v2 to h1 271-273; distance between setae sc2 138; length of legs I-IV (without coxa), leg I 100-102, leg II 81-83, leg III 55-57, leg IV 65-68.

Dorsum (Fig. 5): Propodosoma smooth. Propodosomal and opisthosomal setae serrate, except $d l$ and $e l$ which short and smooth. Prodorsal setae $v 2$ shorter than half distance between their bases. Length of dorsal setae: v2 13-14, sc1 15-16, sc2 19-20, c1 14-15, c2 15-16, c3 19-20, dl 8-9, d3 17-19, el 7-8, e3 22-23, f2 24-25, f3 20-22, hl $19-20, h 222-24$. 


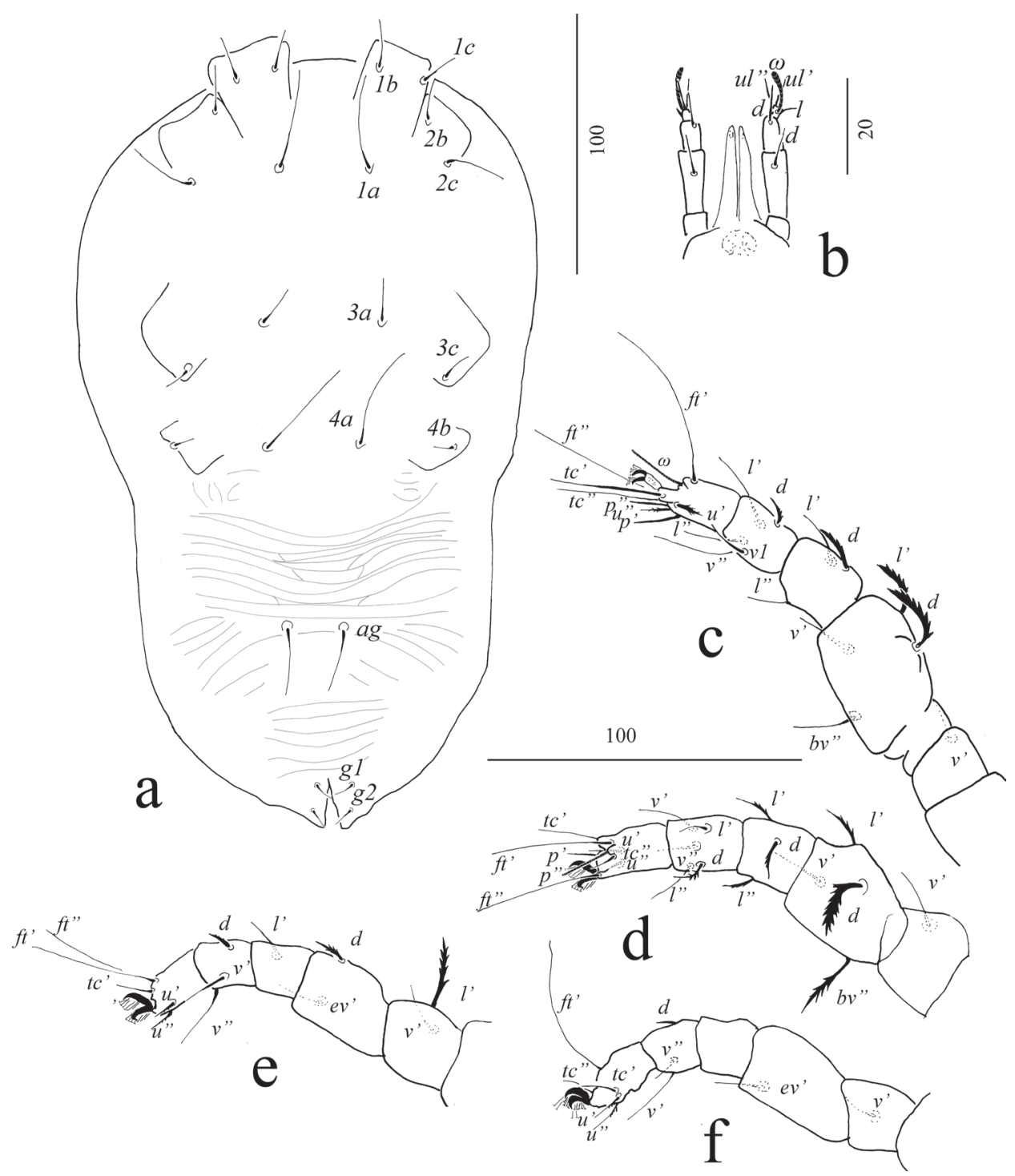

Fig. 4. Cenopalpus lineola (Canestrini and Fanzago, 1876), from Hungary, male: a: ventral view of idiosoma, b: dorsal view of gnathosoma, c: dorsolateral view of leg I, d: dorsolateral view of leg II, e: dorsolateral view of leg III, f: dorsolateral view of leg IV. 


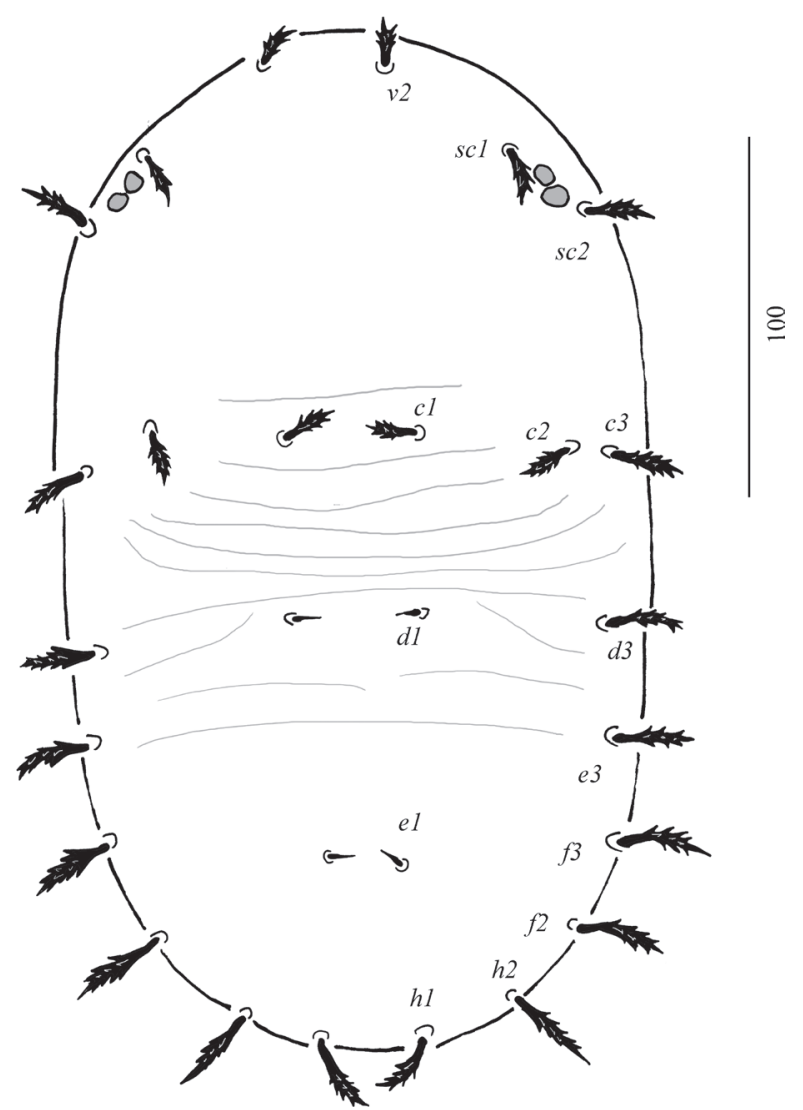

Fig. 5. Dorsal view of Cenopalpus lineola (Canestrini and Fanzago, 1876), from Hungary, deutonymph

Venter (Fig. 6a): Surface of ventral idiosoma with striations. Length of ventral setae, $1 a$ 24-25, 3a 11-12, 4a 45-47, $1 b$ 6-7, 2b 5-6, 3b 19-20, 4b 13-14, 1c 6-8, 2c 5-6, ag 8-9, g 7-8, ps1-2 5-6. All ventral setae simple and smooth.

Gnathosoma: Palp setal counts (Fig. 6b): tarsus with one solenidion, two eupathidia and a seta, tibia and genu with with one-one dorsal setae. All setae smooth.

Legs (Fig. 6c-f): Setal formula for leg I-IV (coxae to tarsi): 3-1-4-3-4-9, 2-1$3-2-3-9,2-2-2-1-3-5,2-0-1-0-3-5$. A part of setae serrate. Solenidia on tarsi I and II 16-22 long, finger-like. Tarsal claws uncinate and empodium pad-like.

Protonymph $(\mathrm{n}=3)$

Idiosoma reddish-brown, oval in shape, body measured from v2 to h1 215-222; distance between setae sc2 115-120; length of legs I-IV (without coxa), leg I 65-68, leg II 58-62, leg III 47-50, leg IV 41-45.

Dorsum (Fig. 7): Propodosoma smooth with some longitudinal striae. Propodosomal and opisthosomal setae serrate, except $d l$ and $e l$ which short and smooth. Prodorsal setae $v 2$ shorter than half distance between their bases. Length of dorsal setae: $v 2$ 12-13, 


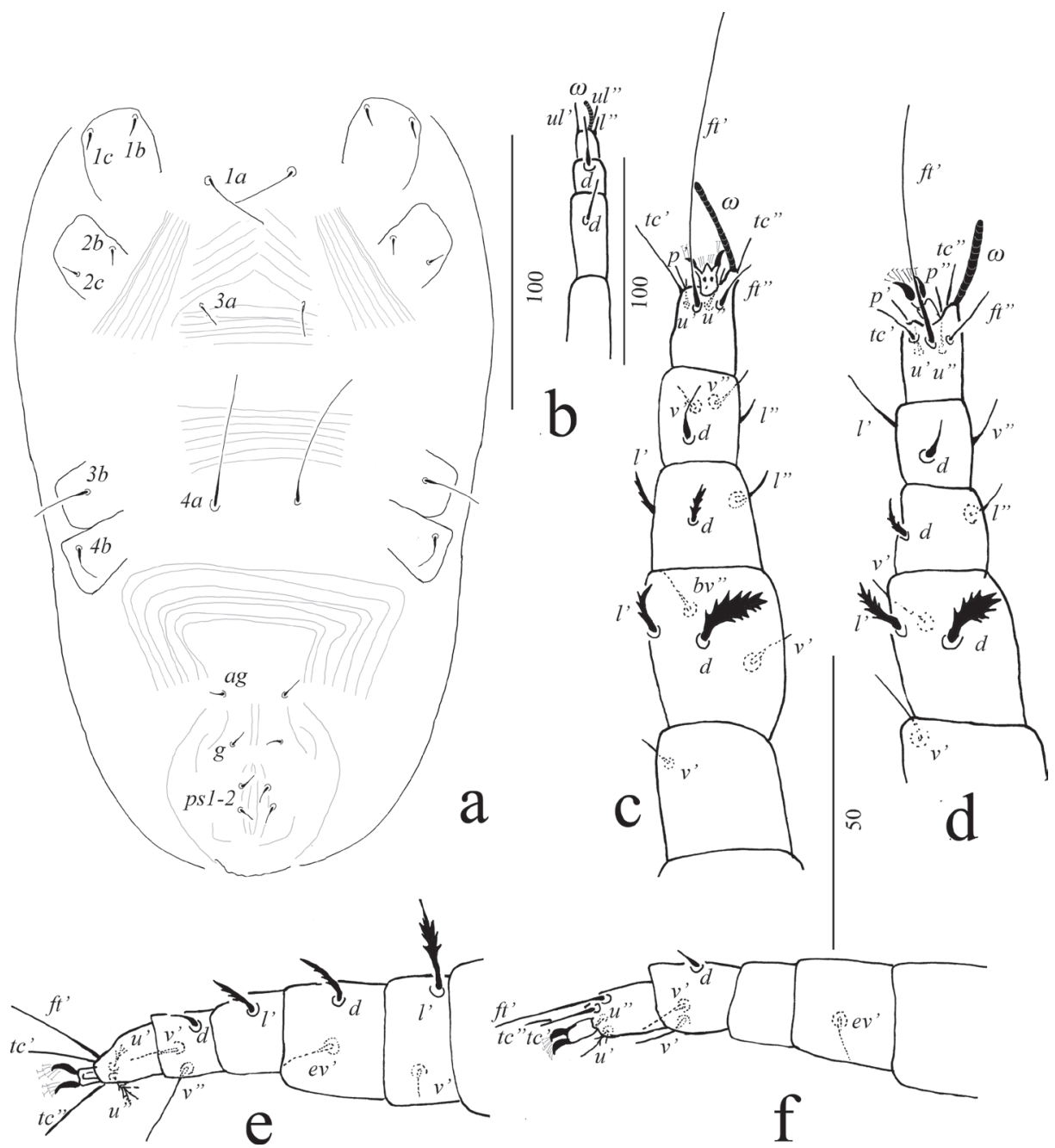

Fig. 6. Cenopalpus lineola (Canestrini and Fanzago, 1876), from Hungary, deutonymph: a: ventral view of idiosoma, b: dorsal view of palp, c: dorsal view of leg I, d: dorsal view of leg II, e: dorsolateral view of leg III, f: dorsolateral view of leg IV.

sc1 12-14, sc2 16-18, cl 14-15, c2 15-17, c3 19-20, dl 6-7, d3 17-19, el 5-7, e3 19-20, f2 19-21,f3 20-21, h1 13-15, h2 20-21.

Venter (Fig. 8a): Surface of ventral idiosoma with striations. Length of ventral setae, $1 a$ 30-32, 3a 7-9, $1 b$ 6-8, $2 b$ 13-14, 3b 6-7, 1c 6-8, ag 8-9, g 7-8, ps 1-2 4-5. All ventral setae simple and smooth.

Gnathosoma: Palp setal counts (Fig. 8b): tarsus with one solenidion, two eupathidia and a seta, tibia and genu with with one-one dorsal setae. All setae smooth.

Legs (Fig. 8c-f): Setal formula for leg I-IV (coxae to tarsi): 3-0-3-1-5-7, 1-0$3-1-4-7,2-1-2-1-3-5,0-0-1-0-3-5$. A part of setae serrate. Solenidia on tarsi I and II 15-19 long, finger-like. Tarsal claws uncinate and empodium pad-like. 


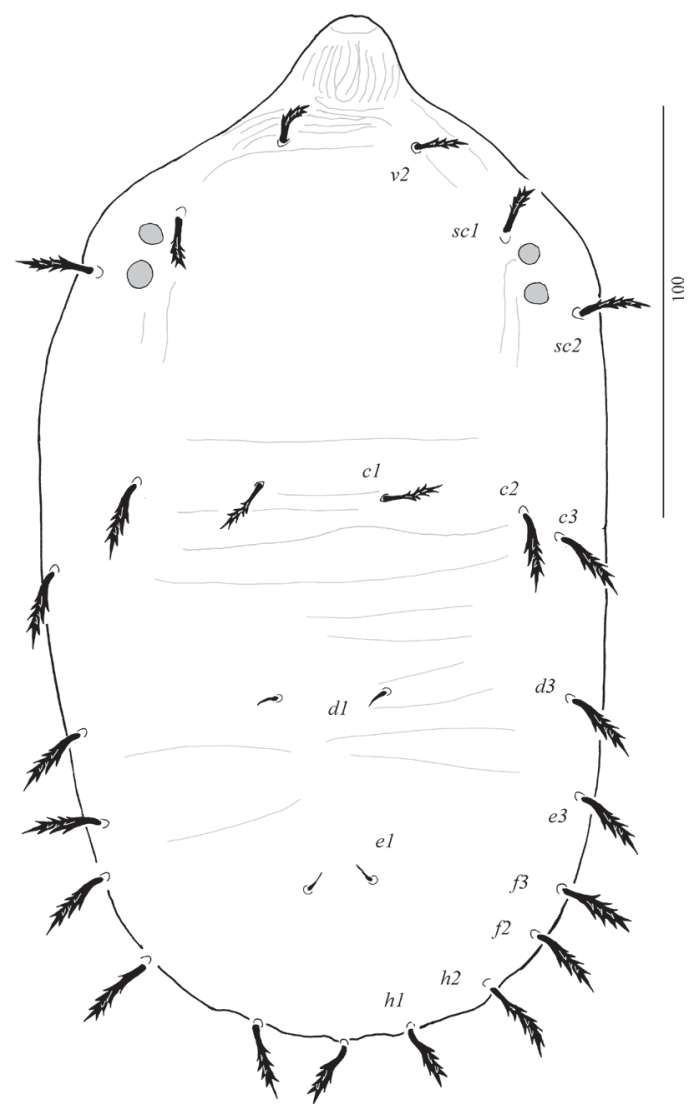

Fig. 7. Dorsal view of Cenopalpus lineola (Canestrini and Fanzago, 1876), from Hungary, protonymph

Notes to the leg setation

Majority of the dorsal setae $(d)$, some lateral ( $b v^{\prime \prime}$ and $l$ ') setae and setae ( $u$ '- $u$ ”) are serrate or pilose in all stages of this species. The other setae are smooth. The solenidia $(\omega)$ of the legs I and II in all stages are very long, longer than the tarsal claws. The Table 1 shows the setation of the legs. Supplementary setae are presented on femora of leg I in females (setae $l^{\prime}$ '), on femora of leg I and leg II in males (setae $l^{\prime}$ ), and on femora of leg I and leg II in deutonymphs (setae $l$ '), and on the tibiae of leg I on females (setae $l$ ") and on the tibiae of legs I and II on males (setae $l$ "). These supplementary setae are absent in protonymphs.

\section{Discussion}

Cenopalpus lineola seems to be a Mediterranean or subtropical pine-inhabiting flat mite species. Till today it was collected in the countries around the Mediterranean Sea (e.g. Greece (Hatzinikolis and Emmanouel, 1987), Italy (Pegazzano, 1971), France (Gutierrez 


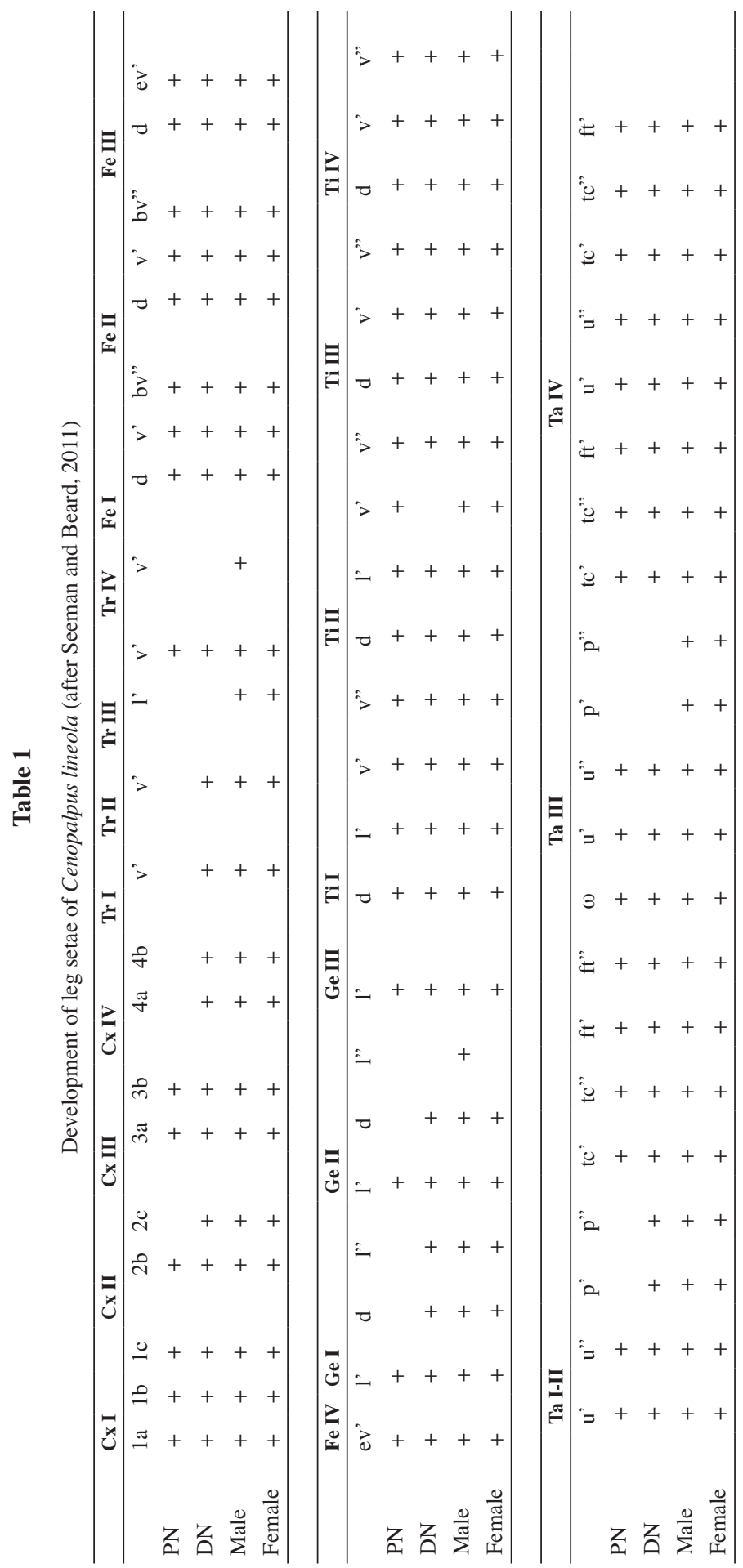




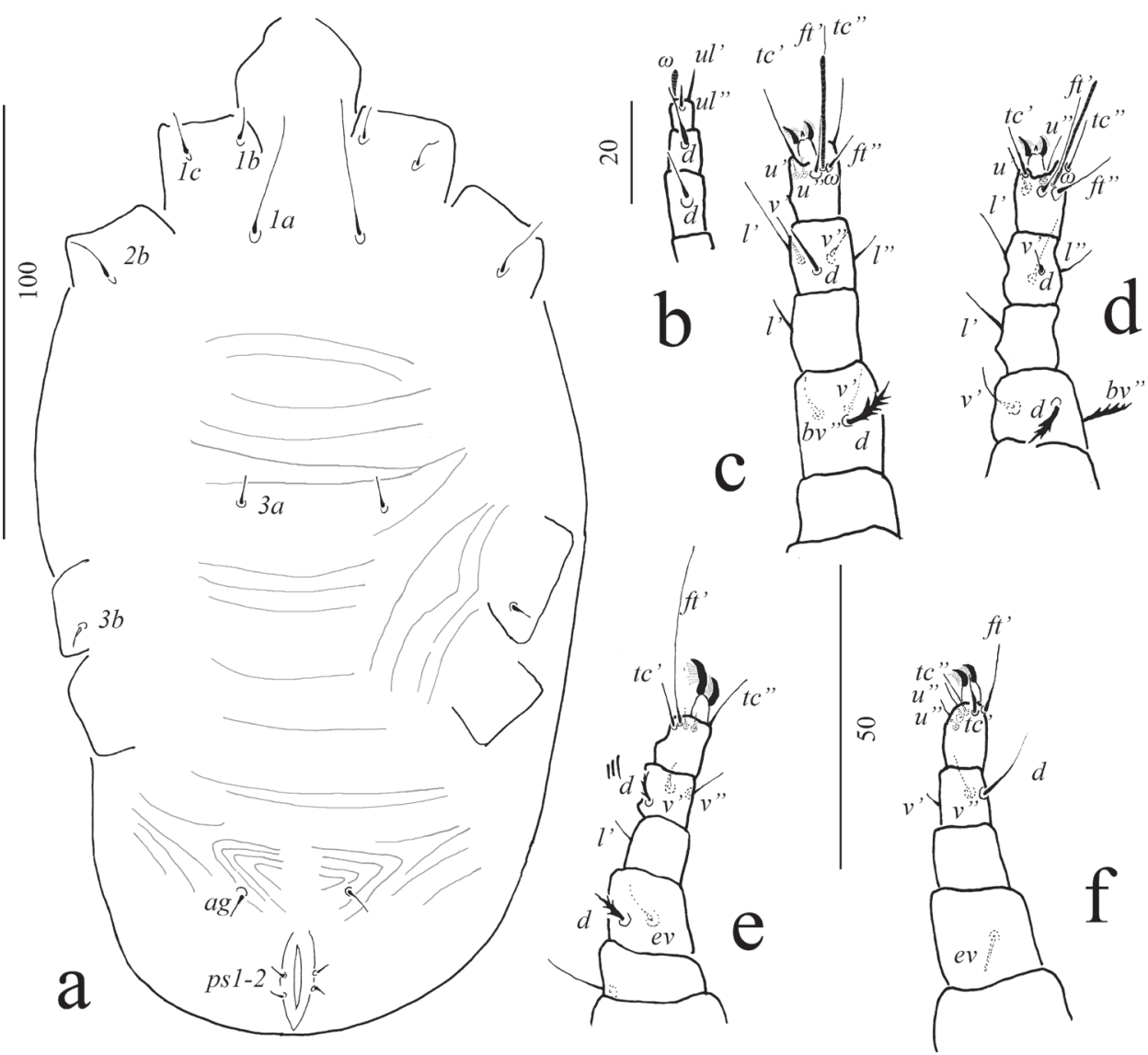

Fig. 8. Cenopalpus lineola (Canestrini and Fanzago, 1876), from Hungary, protonymph: a: ventral view of idiosoma, b: dorsal view of palp, c: dorsal view of leg I, d: dorsal view of leg II, e: dorsal view of leg III, f: dorsal view of leg IV.

et al., 1989), Algeria, Morocco, Tunisia, Lebanon (Dosse, 1974), Israel (Ueckermann et al., 2018) and the countries close to Black Sea (like: Kazakhstan and Georgia (Mitrofanov and Strunkova, 1979), but it was collected in the subtropical Japanese island, Okinawa as well (Ehara, 1966). The Hungarian occurrences are very strange, because the climate of Hungary differs from the latter mentioned regions. Therefore this species is very rare in Hungary; we presume that this species can occur in specific dry and hot habitats, where the host plants were planted. The most important question is whether this species is native to Hungary in these habitats or it was introduced with the host plants from the Mediterranean countries. In Hungary Pinus sylvestris is an indigenous pine species.

On the other hand, the Hungarian specimens of Cenopalpus lineola are closer to the specimens collected in the countries of the post-Soviet states and Japan, than that of the other countries. The setae $e l$ and $d l$ are smooth in the Hungarian specimens, similar to the illustrated mites by Mitrofanov and Strunkova (1979) and Ehara (1966), contrary with Ueckermann et al. (2018) where the illustrated setae are pilose. 


\section{Acknowledgements}

This study was supported by the NKFIH (OTKA) 108663 and by the János Bolyai Research Scholarship of the Hungarian Academy of Sciences and by EFOP-3.6.3- VEKOP-16-2017-00008 project. The project was co-financed by the European Union and the European Social Fund.

\section{Literature}

Bozai, J. (1974): Újabb adatok Magyarország Tetranychoidea faunájához (Acari). (Neue Angaben zur Kenntnis der Tetranychoiden-Fauna Ungarns (Acari).) Folia Entomol. Hung., 27, 5-7.

Canestrini, G. and Fanzago, F. (1876): Nuovi acari Italiani. Atti. Acad. Cien. Veneto, Trentino, Istriana, Pádua, Italy, 5, 130-142.

Dosse, G. (1974): Injurious mite species on Pinus (Acari). Z. Pflanz. Bodenkunde, 81, 364-371.

Ehara, S. (1966): The tetranychoid mites of Okinawa Island (Acarina: Prostigmata). Jour. Fac. Sci. Hokkaido Univ. Ser. Zool., 16, 1-22.

Gutierrez, J., Kreiter, S., Bolland, H. R. and Cotton, D. (1989): Cinq espèces de Tenuipalpidae (Acari, Tetranychoidea) vivant en France sur conifères et trois de leurs prédateurs caryotype d'Oligomerismus oregonensis. Acarologia, 30, 51-58.

Hatzinikolis, E. N. and Emmanouel, N. G. (1987): A revision of genus Cenopalpus in Greece (Acarina: Tenuipalpidae). Entomol. Hell., 5, 13-26. doi: 10.12681/eh.13943

Kontschán, J. and Ripka, G. (2017): Checklist of the Hungarian spider mites and flat mites (Acari: Tetranychidae and Tenuipalpidae). Syst. Appl. Acarol., 22, 1199-1225.

Kontschán, J. and Ripka, G. (2018): A new species of Aegyptobia and redescription of Tenuipalpus szarvasensis Bozai, 1970 (Acari, Tenuipalpidae). Zookeys, 785, 99-115. doi: 10.3897/zookeys.785.27684

Mesa, N. C., Ochoa, R., Welbourn, W. C., Evans, G. and Moraes, G. J. de (2009): A catalog of the Tenuipalpidae (Acari) of the world with a key to genera. Zootaxa, 2098, 1-185.

Mitrofanov, V. and Strunkova, Z. I. (1979): Opredelitelj kleshchej-ploszkotelok. Izdateljsztvo „Donis” Dushanbe, 148 p.

Pegazzano, F. (1971): Osservazioni su Brevipalpus lineola G. Can. and Fan., e su B. waisnteini Livsh. e Mitrof. (Acarina: Tenuipalpidae) infeudati al gen. Pinus in Italia. Redia, 52, 739-753.

Seeman, O. D. and Beard, J. J. (2011): A new species of Aegyptobia (Acari: Tenuipalpidae) from Myrtaceae in Australia. Syst. Appl. Acarol., 16, 73-89.

Ueckermann, E. A., Palevsky, E., Gerson, U., Recht, E. and Theron, P. D. (2018): The Tenuipalpidae (Acari: Trombidiformes) of Israel. Acarologia, 58, 483-525.

Open Access statement. This is an open-access article distributed under the terms of the Creative Commons Attribution 4.0 International License (https://creativecommons.org/licenses/by/4.0/), which permits unrestricted use, distribution, and reproduction in any medium, provided the original author and source are credited, a link to the CC License is provided, and changes - if any - are indicated. (SID_1) 